\title{
Study of the Rational Number of Cutters in the Cutting Lines of Cutting Drum of Geokhod
}

\author{
Aleksei A. Khoreshok \\ Mining department \\ T.F. Gorbachev Kuzbass State Technical University \\ Kemerovo, Russian Federation \\ haa.omit@kuzstu.ru \\ Kirill A. Ananiev \\ Mining department \\ T.F. Gorbachev Kuzbass State Technical University \\ Kemerovo, Russian Federation \\ oneflow@yandex.ru
}

\begin{abstract}
Geokhod with cutting drum leads to inequality of the cutter feed speed to face. For this reason, the number of cutters cannot be the same in all cutting lines and will increase as the distance of cutting line from the center of geokhod to the periphery. The variability of possible schemes with different numbers of cutters leads to the problem of determining the rational number of cutters in the cutting lines on the Geokhod's cutting drum. The definition of a rational number of cutters based on the comparison of structural and kinematic parameters for the various schemes, including identified parameters having the greatest influence on the selection of a rational solution.
\end{abstract}

Keywords — geokhod, cutting drum, picks, cutting lines

\author{
Vladimir V. Aksenov \\ Laboratory of geotechnics \\ SB RAS Kemerovo Science Center \\ Kemerovo, Russian Federation \\ 55vva42@mail.ru \\ Aleksander N. Ermakov \\ Mining department \\ T.F. Gorbachev Kuzbass State Technical University \\ Kemerovo, Russian Federation \\ ermakovan@kuzstu.ru
}

\section{INTRODUCTION}

The search of ways to reduce the cost and speed of mining workings for various purposes has led to the development and creation of a new class of mining machines - Geokhods. [1-4]. Geokhod's prototype of a $3.2 \mathrm{~m}$ diameter is equipped with cutting drums for crushing rocks with numbers from 1 to 5 of Protodyakonov Rock Strength Scale [5-7].

The movement of the Geokhod along the working axis is performed by the rotation of the head section 1 (Figure 1) relative to the tail section 2 due to the interaction of the screw blades with out of cross-section grooves. The rotation of the tail section is prevented by counter rotation blocks 4 . Two cutting drums 5 are crushing the rock and allowing the axial movement of the Geokhod. Screw feed of cutting drums to the face leads to the different feed speed of the cutters mounted on drums in different cutting lines.

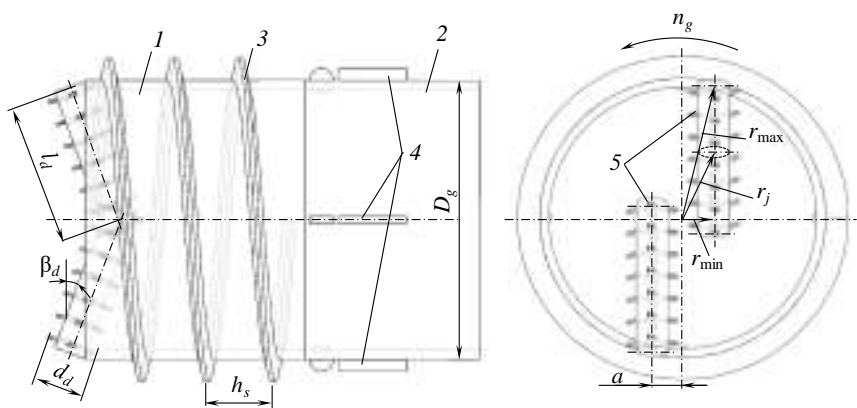

Fig. 1. The scheme and main parameters of Geokhod

When the cutting line is moved from the center of the Geokhod to the periphery, the feed rate increases according to equation (1). This is a difference between the work of cutting drums of the Geokhod from the work of cutting drums of shearers and continuous miners.

$$
V_{h j}=n_{g} \sqrt{h_{s}^{2}+\left(\pi r_{j}\right)^{2}}
$$


In the type: $n_{g}$ stands for the rotation frequency head section of Geokhod; $h_{s}$ stands for the helix pitch distance of screw blade; $r_{j}$ stands for the radius of the position of the $j$-cutting line on the drum relative to the center of the Geokhod.

The difference in feed speeds leads to a change in cutting depth in the different cutting lines. For the prototype (the parameters are given in Table 1) the feed speed of the cutters in the central and peripheral parts differ more than fourfold. Cutting depth changes the same way. This means that if the maximum cutting depth in the central cutting line is $10 \mathrm{~mm}$, then on the border of the shell it will be more than $40 \mathrm{~mm}$ with the same number of cutters in these cutting lines.

TABLE I. THE PARAMETERS OF THE PROTOTYPE OF GEOKHOD

\begin{tabular}{|l|l|l|l|}
\hline \multicolumn{1}{|c|}{ Parameter } & Value & \multicolumn{1}{|c|}{ Parameter } & Value \\
\hline $\begin{array}{l}\text { The outer diameter of } \\
\text { Geokhod, } D_{g}, \mathrm{~m}\end{array}$ & 3,2 & $\begin{array}{l}\text { The angle between } \\
\text { drum axis and face } \\
\text { plane, } \beta_{d}, \mathrm{deg}\end{array}$ & 12 \\
\hline $\begin{array}{l}\text { The helix pitch distance of } \\
\text { screw blade, } h_{s}, \mathrm{~m}\end{array}$ & 0,8 & $\begin{array}{l}\text { Drum } \\
\text { diameter, } d_{d}, \mathrm{~m}\end{array}$ & 0,667 \\
\hline $\begin{array}{l}\text { The offset between the axis } \\
\text { of the rotation of cutting } \\
\text { drums and the main axis of } \\
\text { the Geokhod } a, \mathrm{~m}\end{array}$ & 0,35 & $\begin{array}{l}\text { Maximum rotation } \\
\text { frequency of head } \\
\text { section of Geokhod } \\
n_{g}, \mathrm{~s}^{-1}\end{array}$ & $1 / 600$ \\
\hline Drum length $l_{d}, \mathrm{~m}$ & 1,51 & \multicolumn{2}{|l}{} \\
\hline
\end{tabular}

Such a range in the cutting depths is not rational. At low values of the cutting depth, there will be a high specific energy of the rock destruction process [8]. When values of the cutting depth are high, the destruction of the cutters will occur. The way out of this situation is a gradual increase in the number of cutters in the cutting lines from the minimum in the central zone to the maximum in the peripheral.

A large number of variants of possible schemes of sets of cutting tools on the executive body determines the research task: the determination for the rational number of cutters in the cutting lines on the cutting drum of the prototype of the Geokhod.

\section{METHODS}

To solve the task it is required:

1) to develop schemes with different numbers of cutters (structural schemes);

2) to determine of parameters for the evaluation of structural schemes;

3) the analysis of structural schemes.

In this paper, four variants of structural schemes are considered: with two, three, four and five cutters in peripheral cutting lines.

As parameters for the evaluation of structural schemes, the following are taken: the total cutting path of the cutters in one turn of the drum $(L)$, the average depth of cut $\left(h_{m}\right)$, the specific energy of the destruction of the rock $\left(H_{w}\right)$, and the total number of cutters on the drum $(z)$.

The total cutting path of the cutters is equal to the sum of the paths of every cutter $L_{i}$. The cutting path of the $i$-cutter is determined by the equation:

$$
\frac{L_{i}=\int_{\varphi 1}^{\varphi_{2}} \sqrt{\left(a+\frac{d_{d}}{2}\left(1+i_{\omega} \cos \beta_{d}\right) \cos i_{\omega} \varphi\right)^{2}+\left(l_{i} \sin \beta_{d}+\right.}}{\left.+\frac{d_{d}}{2}\left(i_{\omega}+\cos \beta_{\sigma}\right) \sin i_{\omega} \varphi\right)^{2}+\left(\frac{h_{s}}{2 \pi}-i_{\omega} \frac{d_{d}}{2} \sin \beta_{d} \cos i_{\omega} \varphi\right)^{2}}
$$

In the type: $l_{i}$ stands for a position of the $i$-cutting line relative to the lower drum base $\left(0 \leq l_{i} \leq l_{d}\right), \mathrm{m} ; i_{\omega}$ stands for the ratio of rotation frequencies of the head section of the Geokhod and cutting drums; $\varphi_{1}$ and $\varphi_{2}$ are angles of revolution of the drum, at which the beginning and the end of the cutting occur; $\varphi$ is current angle of revolution of the drum within the cutting range $\left(\varphi_{1} \leq \varphi \leq \varphi_{2}\right)$.

Since the cutting conditions for each circuit solution will be similar, we consider the specific energy of the rock destruction to be the same for any of the structural schemes.

The average cutting depth $\left(h_{m}\right)$ is interrelated with the maximum cutting depth $\left(h_{\max }\right)$. The relationship is determined by the angle of coverage $(\gamma)$ of the drum $\left(\gamma=\varphi_{1}-\varphi_{2}\right)$ by the equation:

$$
h_{i m}=h_{i \max } \frac{1-\cos \gamma}{\gamma}
$$

The actual maximum depth of cutting in an uncertain cutting line $\left(h_{\text {imax }}\right)$ is described by the expression.

$$
h_{i \max }=\frac{n_{g} \sqrt{h_{s}^{2}+\left(\pi r_{j}\right)^{2}}}{n_{d} z_{j}}
$$

In the type: $z_{j}$ stands for the number of cutters in the $j$-cutting line; $n_{d}$ is rotation frequency of cutting drums.

The maximum cutting depth depends on the rotation frequency of the cutting drum $\left(n_{d}\right)$. The required rotation frequency of the cutting drums can be determined by the maximum permissible cutting depth $\left(h_{p}\right)$. The maximum permissible cutting depth is given or is based on ensuring a rational mode of cutting of the rock or parameters of the cutter. The cutting drum rotation frequency should have a value at which the actual maximum cutting depth in the peripheral cutting line is equal to the maximum permissible:

$$
n_{d}=\frac{V_{h \max }}{h_{p} z_{p}} \text { or } n_{d}=\frac{n_{g} \sqrt{h_{s}^{2}+\left(\pi r_{\max }\right)^{2}}}{h_{p} z_{p}}
$$

In the type: $z_{p}$ stands for the number of cutters in peripheral cutting line; hp is the maximum permissible cutting depth.

\section{RESULTS AND DISCUSSION}

Table 2 presents the values of the parameters of various structural schemes of the cutting drums of the prototype of the Geokhod, determined by equations (2) - (5). The maximum permissible cutting depth is taken as $24 \mathrm{~mm}$ and the distances between cutting lines as $31 \mathrm{~mm}$ [9]. 
TABLE II. THE PARAMETERS OF STRUCTURAL SCHEMES OF CUTTING DRUMS WITH A VARIABLE THE NUMBER OF CUTTERS IN PERIPHERAL CUTTING LINE S

\begin{tabular}{|l|l|l|l|l|}
\hline \multirow{2}{*}{ Parameter } & \multicolumn{4}{c|}{$\begin{array}{c}\text { Number of cutters in } \\
\text { peripheral cutting line }\end{array}$} \\
\cline { 2 - 5 } & $\mathbf{2}$ & $\mathbf{3}$ & $\mathbf{4}$ & $\mathbf{5}$ \\
\hline $\begin{array}{l}\text { Rotation frequency } \\
\text { of cutting drums, RPM }\end{array}$ & 22,8 & 15,0 & 11,4 & 9,0 \\
\hline Number of cutters on cutting drums & 45 & 62 & 78 & 97 \\
\hline $\begin{array}{l}\text { Total cutting path of the cutters } \\
\text { in one turn of the Geokhod }\end{array}$ & 5878 & 5403 & 5240 & 5171 \\
\hline
\end{tabular}

In the table, there are no maximum and average cutting depths as they differ depending on the position of the cutter on the drum. Fig. 2 shows the graphs of the variation of the maximum cutting depths, formed according to equation (4) for two different structural schemes.

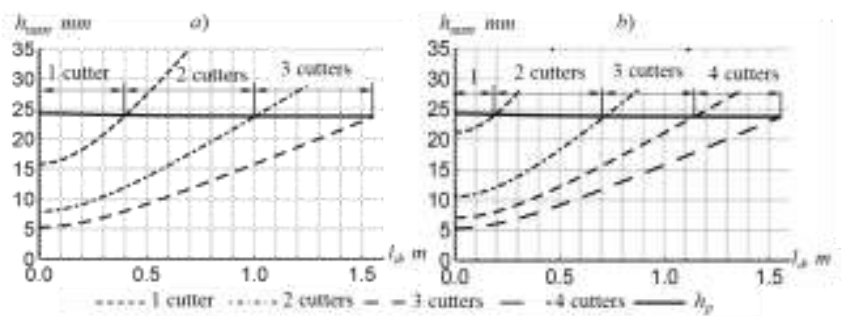

Fig. 2. Dependence of the maximum cutting depth on the position of the cutting line on the drum with three cutters in the peripheral cutting line (a) and four cutters in the peripheral cutting line (b)

The analysis of the graphs in Fig. 2 show that for different variants of schemes the proportion of cutters working with a higher depth of cutting is not the same. To determine the rational number of cutters in the peripheral cutting lines, it is necessary to take into account the regularity of the cutting depths in different areas of the drum. Fig. 3 shows the histograms of the distribution of the average cutting depths obtained by the equation (3).
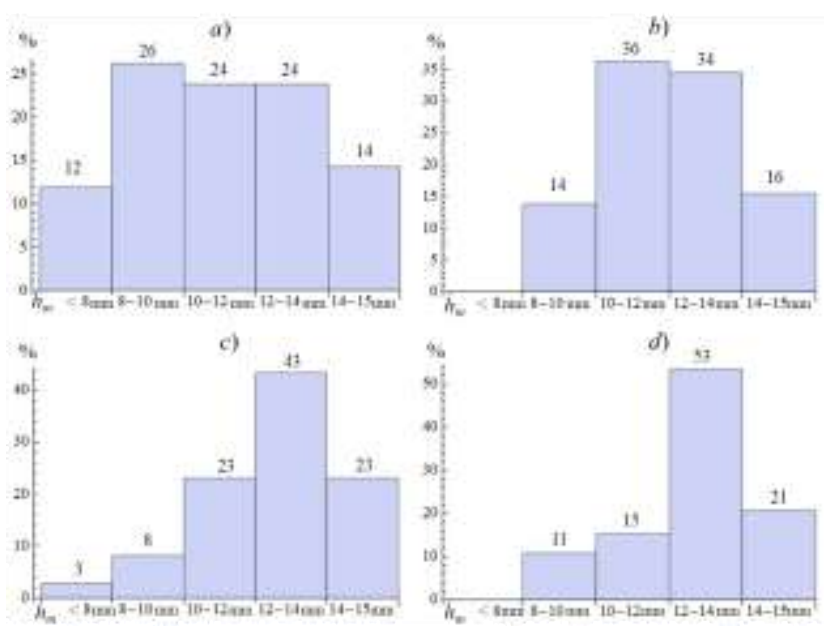

Fig. 3. Histograms of the distribution of the average cutting depths on cutters: a) - two cutters in peripheral cutting line; b) - three cutters in peripheral cutting line; $c$ ) - four cutters in peripheral cutting line; $d$ ) -five cutters in peripheral cutting line

For the scheme with two cutters in the peripheral cutting line (Fig. 3, a), 38\% of cutters work with an average cutting depth of less than $10 \mathrm{~mm}$, and $12 \%$ with an average cutting depth of 6-8 $\mathrm{mm}$. while reducing the cutting depth does not decrease the abrasive wear of the tool. For the other schemes,
$86 \%$ of the cutters work in the cutting depth range of $10-15$ $\mathrm{mm}$ with three cutters in the peripheral cutting lines, while $89 \%$ operate with four and five cutters. The maximum difference in the parameters of the total cutting path for three, four and five cutters (Table 2) is $4 \%$.

The number of cutters on the drum is more significantly different. Comparing schemes with three and four cutters, the difference is 16 cutters or $20 \%$. The same percentage will be obtained comparing the schemes with four and five cutters.

\section{CONCLUSIONS}

1) The scheme with two cutters in the peripheral cutting line of the cutting drums of the proto-type of the Geokhod is not rational. $50 \%$ of the cutters work with a cutting depth of less than $10 \mathrm{~mm}$.

2) The main factor for the evaluation of structural scheme with three, four and five cutters is the total number of cutters on the drum. On the other criteria there is equality.
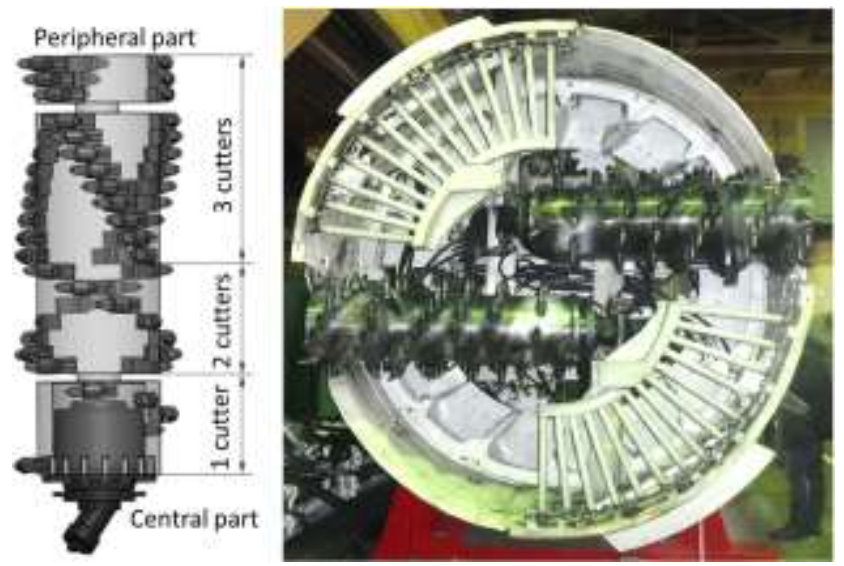

Fig. 4. Cutting drum with a rational number of cutters and a prototype of a Geokhod

3) The rational number of cutters on the cutting drum of the prototype of the Geokhod is 62 cutters with three cutters in the peripheral cutting line (Fig. 4).

Based on the results obtained, the cutting drums of the prototype of the Geokhod was designed and produced (Fig. 4).

The offered method to determine the rational number of cutters on the cutting drums of the prototype model of the Geokhod can be used for other dimensions or diameters, as well as for other mining combines with planetary cutting drums.

\section{ACKNOWLEDGMENT}

The research was sponsored by Grant of the President of the Russian Federation for state support of young Russian scientists MK-664.2018.8.

\section{REFERENCES}

[1] Aksenov V. V., Beglyakov V. Yu.., Blashchuk M. Yu., Efremenkov A. B., Kazantsev A. A., Khoreshok A. A., Walter A. V. Geokhod; Objectives, Characteristics, Prospect[J]. Mining equipment and electromechanics, 2016, 8(126): 3-8.

[2] Aksenov V. V., Khoreshok A. A., Beglyakov V. Yu..Justification of creation of an external pro-pulsor for multipurpose shield-type 
heading machine-GEO-WALKER[J]. Applied mechanics and materials. Trans Tech Publications, 2013, Vol. 379: 20-23.

[3] Aksenov V. V., Khoreshok A. A., Ananyev K. A., Yermakov A. N. Development of schemes of executive bodies of subterrenes [J]. News of the Higher Institutions. Mining Journal, 2014, 3: 73-76.

[4] Khoreshok A. A., Ananyev K. A. Determination of Geometrical and Setting Parameters of Geokhods Experimental Model Cutting Drums [J]. Mining equipment and electromechanics, 2016, 8(126): 30-33.

[5] Pushkina, N.B. Razrabotka metodov i programmnyh sredstv proektirovanija ispolnitel'nyh organov vintopovorotnyh prohodcheskih agregatov (na primere agregata JeLANG): avtoref. dis. ... kand. tehn. nauk. Kemerovo, 1991.

[6] Kui-Dong G., Chang-Long D., Hong-Xiang J. Drum Cutting Specific Energy Consumption Model Built by Cutting Curves Analysis [J]. TELKOMNIKA, 2013, Vol. 11, №7: 4122-4128.

[7] Xuefeng Li, Shibo Wang, Shirong Ge, et al. A study on drum cutting properties with full-scale experiments and numerical simulations [J]. Measurement, 2018, 114: 25-36.

[8] Park Jin-Young, Kang Hoon, Lee Jae-Wook, et al. A study on rock cutting efficiency and struc-tural stability of a point attack pick cutter by lab-scale linear cutting machine testing and finite ele-ment analysis [J]. International Journal of Rock Mechanics and Mining Sciences, 2018, 103: 215-229.

[9] Maleev G.V., Guljaev V.G., Bojko N.G., et al. Design and construction of mining machines and complexes [M]. Moscow, Nedra, 1988. 